\title{
Evaluating the First Type of Seizure and Variety of Seizures in Resistance Epileptic Patients
}

\author{
Fatma Çetinkaya Çat ${ }^{1}$ (D), Mehmet Sait Okan² (10) \\ 1'Department of Pediatrics, University of Health Sciences Gaziosmanpaşa Taksim Training and Research Hospital, i̇stanbul, Turkey \\ 2Department of Pediatric Neurology, Uludağ University School of Medicine, Bursa, Turkey
}

Cite this article as: Çetinkaya Çat F, Okan MS. Evaluating the First Type of Seizure and Variety of Seizures in Resistance Epileptic Patients. JAREM 2019; 9(Supplement 1): S29-34.

\begin{abstract}
Objective: Despite the fact that children with epilepsy use multiple antiepileptic drugs, the part of the epileptic group without the seizure control constitutes a resistant epilepsy group. This study evaluates the first type of seizure and the variety of seizures and resistance development that we think might be a risk factor for the development of resistance in epileptic patients.

Methods: Data were obtained retrospectively from the files of patients diagnosed with epilepsy who were monitored for at least 2 years between January 1, 2009, and December 31, 2011, at the Uludağ University School of Medicine; Department of Pediatric Neurology.

Results: One hundred twenty patients were girls (49\%) and 125 were boys (51\%). The age range was $1-18$ years and the median value was 8.3 (1-18) years. One hundred and twenty of the 245 patients who met the diagnostic criteria for resistant epilepsy were found to be well controlled. In patients with resistant epilepsy, the first seizure type and the variety of seizures were compared in these two groups of patients. It was observed that the most common type of seizure seen in the refractory group was myoclonic seizures (25.6\%), whereas the most common type of seizure was generalized seizure with focal onset (34.2\%) in well-controlled group. There was statistically significant difference between groups $(p<0.05)$. In terms of seizure types, it was observed that the refractory group included more patients $(60.7 \%)$ with three or more types of seizure $(p<0.05)$.
\end{abstract}

Conclusion: In this study, we found that the first seizure type and seizure variability were important risk factors for resistance development in epileptic patients.

Keywords: Epilepsy, resistant epilepsy, child, seizure type

\section{INTRODUCTION}

The World Health Organization defines epilepsy as recurrent seizures observed in chronic cerebral dysfunction that is caused by several etiological causes. Although the incidence is approximately $50-100 / 100.000$ in children and adolescents, $4 \%-10 \%$ of this population has seizures at least once until adolescence. There are at least 50 million people affected worldwide, and among these, $80 \%$ is from developing countries, and $80 \%-90 \%$ of the people in these countries receive insufficient treatment or no treatment at all (1, 2-6, 7-9).

The terms "seizure" and "epilepsy" are different concepts and should not be used interchangeably. The exact equivalent for epilepsy is not "seizure," but can be called as "seizure disease." Seizures are signs, but epilepsy is a disease characterized by recurrent seizures. Seizures are paroxysmal symptoms caused by abnormal, involuntary, time-limited rhythmic discharges of neurons. Convulsions are defined as muscle contractions that occur during seizures $(6,10-17)$.
While in most of the children with epilepsy, seizure control is achieved with the use of a single antiepileptic drug, multiple antiepileptic drugs are used in a lesser number; however, seizure control is not achieved. These cases, in which seizure control cannot be maintained despite these multiple antiepileptics, constitute the resistant epilepsy group (18-20).

In the study conducted by Sillanpaa et al. (21) in 2011, resistant epilepsy has been defined as the occurrence of seizures once or more per month despite the effective use of at least two antiepileptic drugs and having a no seizure-free period for at least 3 months. In our study, patients who were followed up at the Uludağ University Pediatric Neurology Polyclinic with epilepsy diagnosis for at least 2 years, who have no seizure-free period for at least 3 months despite taking three or more antiepileptic drugs one by one or in combination and with effective serum level, and who have seizures at least once every month are considered as patients with resistant epilepsy. Drugs used in emergency because of convulsions, used during epileptic status, and discontinued because drug levels could not be es- 
tablished or drug side effects occurred were not included in the three drugs.

\section{Classification in Epilepsy}

Seizures are mainly divided into two main classes as partial and generalized seizures. The International League Against Epilepsy (ILAE) made its international classification of epileptic seizures for the first time in 1981 and reclassified epilepsy and epileptic syndromes in 2010 (22). The classification of epileptic seizures is stated below.

\section{International Classification (ILAE) of Epileptic Seizures}

\section{Partial (Local, Focal) Seizures}

\section{A. Simple Partial Seizures: (No Consciousness Disorder) \\ 1. Seizures with motor symptoms \\ 2. Seizures with somatosensory or special sensory symptoms \\ 3. Seizures with autonomic symptoms or signs \\ 4. Seizures with psychic symptoms}

\section{B. Complex Partial Seizures (Blur of Consciousness Exists)}

1. Seizures followed by simple partial onset of confusion

2. Seizures with confusion from the beginning

\section{Secondary Generalized Partial Seizures}

1. Generalized seizures starting in simple partial form

2. Generalized seizures starting in complex partial form

3. Generalized seizures starting from simple partial and transforming into complex partial

\section{A. Absence of seizures \\ B. Myoclonic seizures \\ C. Tonic seizures \\ D. Clonic seizures \\ E. Atonic seizures \\ F. Tonic-clonic seizures}

II. Generalized Seizures (Convulsive or Nonconvulsive)

\section{Unclassified Epileptic Seizures}

In the studies conducted, the importance of the development of resistant epilepsy, the type of seizures, and the variety of seizures were discussed. The aim of the present study was to evaluate the relationship between the initial seizure type and the variety of seizures that we think may be a risk factor for the development of resistance in patients with epilepsy. We believe that such an evaluation would guide clinicians following patients with resistant epilepsy with respect to treatment and follow-up.

\section{METHODS}

Data of patients who were diagnosed with epilepsy at the outpatient clinic of Uludağ University Pediatric Neurology Department and followed up for at least 2 years between January 01, 2009 and December 31, 2012 were obtained via the analyses of the patient files retrospectively. From the file records of the patients, the type and variety of seizures, gender, and age of the patients were recorded. The files of 1500 patients with epilepsy who were admitted to the Pediatric Neurology outpatient clinic with convulsion between January 2009 and December 2012 were examined. Among the 1500 patients, 245 who were followed up for at least 2 years and who fulfilled the criteria for the diagnosis of resistant epilepsy were included in the study.
Patients who were followed up at the Uludağ University Pediatric Neurology Polyclinic with epilepsy diagnosis for at least 2 years, who had no seizure-free period for at least 3 months despite taking three or more antiepileptic drugs one by one or in combination and with effective serum level, who had seizures at least once every month, and were considered as patients with resistant epilepsy were included in our study. Drugs used in emergency because of convulsions, used during epileptic status, and discontinued because drug levels could not be established or drug side effects occurred were not included in the three drugs. Patients who received at least three antiepileptic drugs in the first 2 years and who did not respond to classical antiepileptic drugs and whose seizures were taken under control after the addition of new generation antiepileptic drugs alone or in addition to classical antiepileptic drugs during follow-up were classified as the well-controlled group. Of the 245 patients who met the diagnostic criteria of resistant epilepsy, 120 were later included in this group. The symptoms of the two groups of patients with resistant epilepsy were compared with respect to the initial seizure type and the variety of seizures. The study was approved by the Uludağ University Ethics Committee (decision dated September 30, 2014, no. 2014-18/3).

\section{Statistical Analysis}

Relationships between variables were analyzed using Statistical Package for Social Sciences version 21.0 (IBM Corp., Armonk, NY, USA). Chi-square test and Fisher's exact test were used to analyze the differences between the frequencies of categorical variables. Shapiro-Wilk test was used to investigate the suitability of data for normal distribution. Mann-Whitney $U$ test was used for comparisons between two independent groups in data that did not conform to normal distribution. Descriptive statistics of data that did not conform to normal distribution were expressed as median (min-max). Significance level was $\alpha=0.05(p<0.05)$.

\section{RESULTS}

The files of 1500 patients with epilepsy who were admitted to the Pediatric Neurology outpatient clinic with convulsions between January 2009 and December 2012 were examined. Among these 1500 patients, 245 of these patients who were followed up for at least 2 years and who fulfilled the criteria for the diagnosis of resistant epilepsy were included in the study. Patients who received at least three antiepileptic drugs in the first 2 years and who did not respond to classical antiepileptic drugs and whose seizures were taken under control after the addition of new generation antiepileptic drugs alone or in addition to classical antiepileptic drugs during follow-up were classified as the well-controlled group. One hundred twenty out of 245 patients who met the diagnostic criteria of resistant epilepsy were later included in this group. The symptoms of the two groups of patients with resistant epilepsy were compared with respect to the initial seizure type and the variety of seizures.

When the distribution of all patients according to gender was examined, it consisted of 120 (49\%) girls and $125(51 \%)$ boys. When we examined the age range of patients with epilepsy evaluated, this distribution ranged between 1 and 18 years, and the median value was found to be $8.3(1-18)$ years. The average age of the resistant group was $7.8 \pm 4.7$ years, and the average age of the 
well-controlled group was $9 \pm 4.8$ years. The follow-up period of the patients was between 3.5 and 14.8 (average 7.4 \pm 2.1 ) years.

When the distribution of patients according to the initial seizure type was examined, six (2.4\%) cases were included in the simple partial seizures group. Of the six patients, five (83.3\%) were in- cluded in the well-controlled group, whereas one (16.7\%) was included in the resistant group. The number of cases with partial complex seizures was four $(1.6 \%)$, of which one (25\%) was in the resistant group and three (75\%) were in the well-controlled group. The number of cases with focal onset generalized seizures

Table 1. Distribution of patients according to initial seizure types

\begin{tabular}{|l|c|c|c|c|c|c|}
\hline & \multicolumn{2}{|c|}{ Patient } & \multicolumn{2}{c|}{ Resistant } & \multicolumn{2}{c|}{ Well-controlled } \\
\hline Seizure type & $\mathbf{n}$ & $\%$ & $\mathbf{n}$ & $\%$ & $\mathbf{n}$ & $\%$ \\
\hline Simple partial & 6 & 2.4 & 1 & 0.8 & 5 & 4.2 \\
\hline Complex partial & 4 & 1.6 & 1 & 0.8 & 3 & 2.5 \\
\hline Focal onset generalized & 70 & 28.6 & 29 & 23.2 & 41 & 34.2 \\
\hline Generalized tonic & 57 & 23.3 & 29 & 23.2 & 28 & 23.3 \\
\hline Generalized clonic & 7 & 2.9 & 4 & 3.2 & 3 & 2.5 \\
\hline Generalized tonic-clonic & 18 & 7.3 & 8 & 6.4 & 10 & 8.3 \\
\hline Myoclonic & 49 & 20 & 32 & 25.6 & 17 & 14.2 \\
\hline Atonic & 10 & 4.1 & 2 & 1.6 & 8 & 6.7 \\
\hline Absence & 7 & 2.9 & 6 & 4.8 & 1 & 0.8 \\
\hline Infantile spasm & 17 & 6.9 & 13 & 10.4 & 4 & 3.3 \\
\hline Total & 245 & 100 & 125 & 100 & 120 & 100 \\
\hline
\end{tabular}

\begin{tabular}{|c|c|c|c|c|}
\hline $\begin{array}{l}\text { Simple } \\
\text { partial }\end{array}$ & $\begin{array}{l}\text { Complex } \\
\text { partial }\end{array}$ & $\begin{array}{l}\text { Focal onset } \\
\text { generalized }\end{array}$ & $\begin{array}{l}\text { Generalized }+ \text { Generalized } \\
\text { tonic }\end{array}$ & $\begin{array}{l}\text {-Myoclonic Atonic Absence Infantile } \\
\text { spasm }\end{array}$ \\
\hline
\end{tabular}

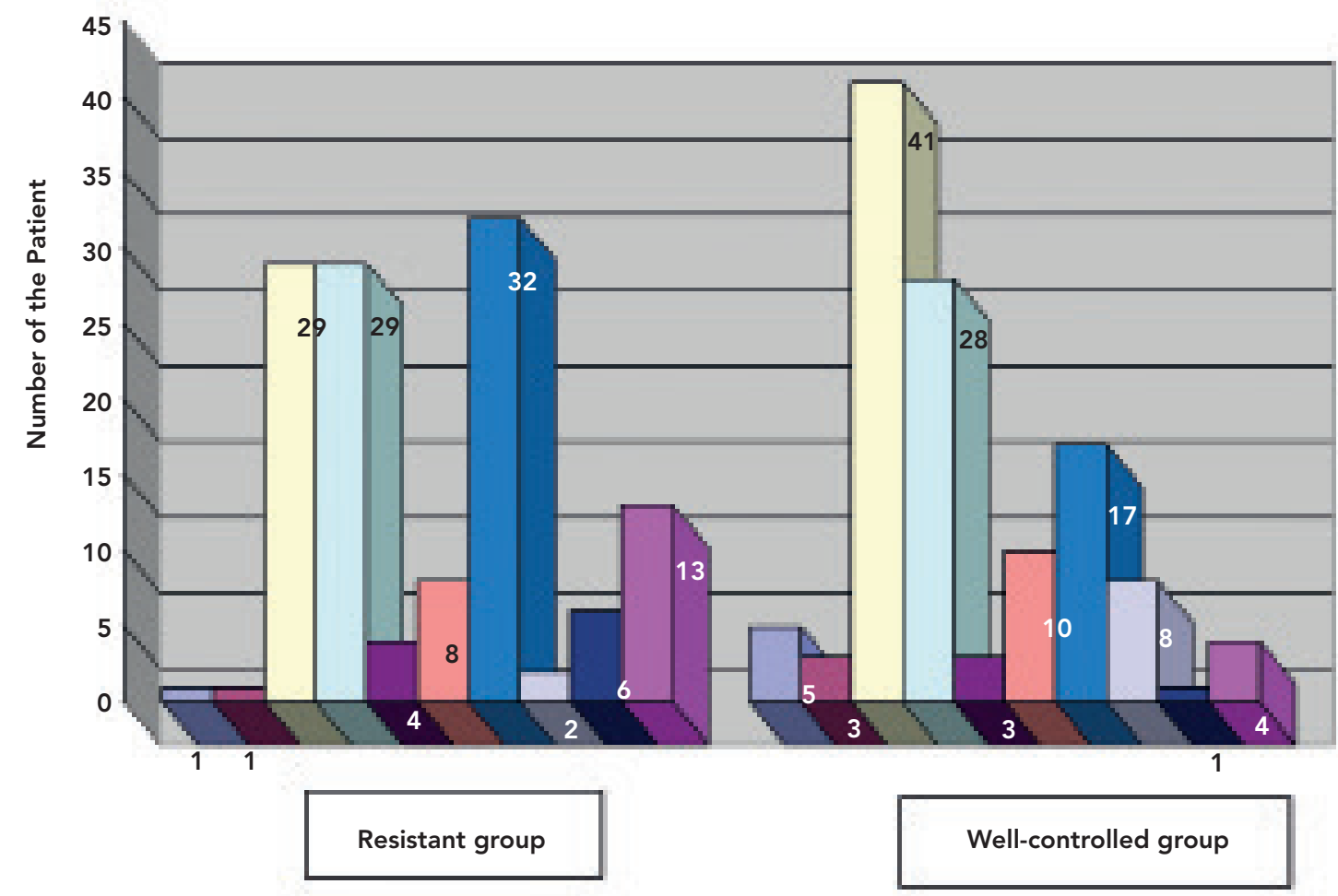

Figure 1. Distribution of patients according to initial seizure types 
was $70(28.6 \%)$, of which $29(41.4 \%)$ were in the resistant group and $41(58.6 \%)$ were in the well-controlled group. The number of cases with generalized tonic seizures was 57 (23.3\%), of which $29(50.9 \%)$ were in the resistant group and 28 (49.1\%) were in the well-controlled group. The number of cases with generalized clonic seizures was seven (2.9\%), of which four $(57.1 \%)$ were in the resistant group and three (42.9\%) were in the well-controlled group. The number of cases with generalized tonic-clonic seizures was 18 (7.3\%), of which $8(44.4 \%)$ were in the resistant group and $10(55.6 \%)$ were in the well-controlled group. The number of cases with myoclonic seizures was 49 (20\%), of which 32 (65.3\%) were in the resistant group and 17 (34.7\%) were in the well-controlled group. The number of cases with atonic seizures was 10 (4.1\%), of which 2 (20\%) were in the resistant group and $8(80 \%)$ were in the well-controlled group. The number of cases with absence of seizure was seven $(2.9 \%)$, of which six (85.7\%) were in the resistant group and one (14.3\%) was in the well-controlled group. The number of cases with infantile spasm was 17 (6.9\%), of which $13(76.5 \%)$ were in the resistant group and 4 (23.5\%) were in the well-controlled group. Table 1 and Figure 1 show the distribution of patients according to the initial seizure types. The most common seizure type was myoclonic seizure $(25.6 \%)$ in the resistant group and focal onset generalized seizure (34.2\%) in the wellcontrolled group. There was a statistically significant difference in seizure type between the two groups $(p=0.001)$.

When patients were evaluated with respect to seizure variety (type and number), there were 33 (13.4\%) cases with a single seizure, of which 12 (36.4\%) were in the resistant group and 21 (63.6\%) were in the well-controlled group. There were 156 (63.7\%) cases with two types of seizures, of which 79 (50.6\%) were in the resistant group and 77 (49.4\%) were in the well-controlled group. The number of cases with three or more seizures was 56 (22.9\%), of which $34(60.7 \%)$ were in the resistant group and 22 (39.3\%) were in the well-controlled group. With respect to seizure diversity (type and number), it was seen that patients who had three or more types of seizures were more frequent in the resistant group (60.7\%), and that a statistically significant difference was found

Table 2. Distribution of patients according to seizure diversity

\begin{tabular}{|l|c|c|c|c|c|c|}
\hline & \multicolumn{2}{|c|}{ Patient } & \multicolumn{2}{c|}{ Resistant } & \multicolumn{2}{c|}{ Well-controlled } \\
\hline Seizure diversity & $\mathbf{n}$ & $\%$ & $\mathbf{n}$ & $\%$ & $\mathbf{n}$ & $\%$ \\
\hline Single & 33 & 13.4 & 12 & 9.6 & 21 & 17.5 \\
\hline Double & 156 & 63.7 & 79 & 63.2 & 77 & 64.2 \\
\hline Three or more & 56 & 22.9 & 34 & 27.2 & 22 & 18.3 \\
\hline Total & 245 & 100 & 125 & 100 & 120 & 100 \\
\hline
\end{tabular}

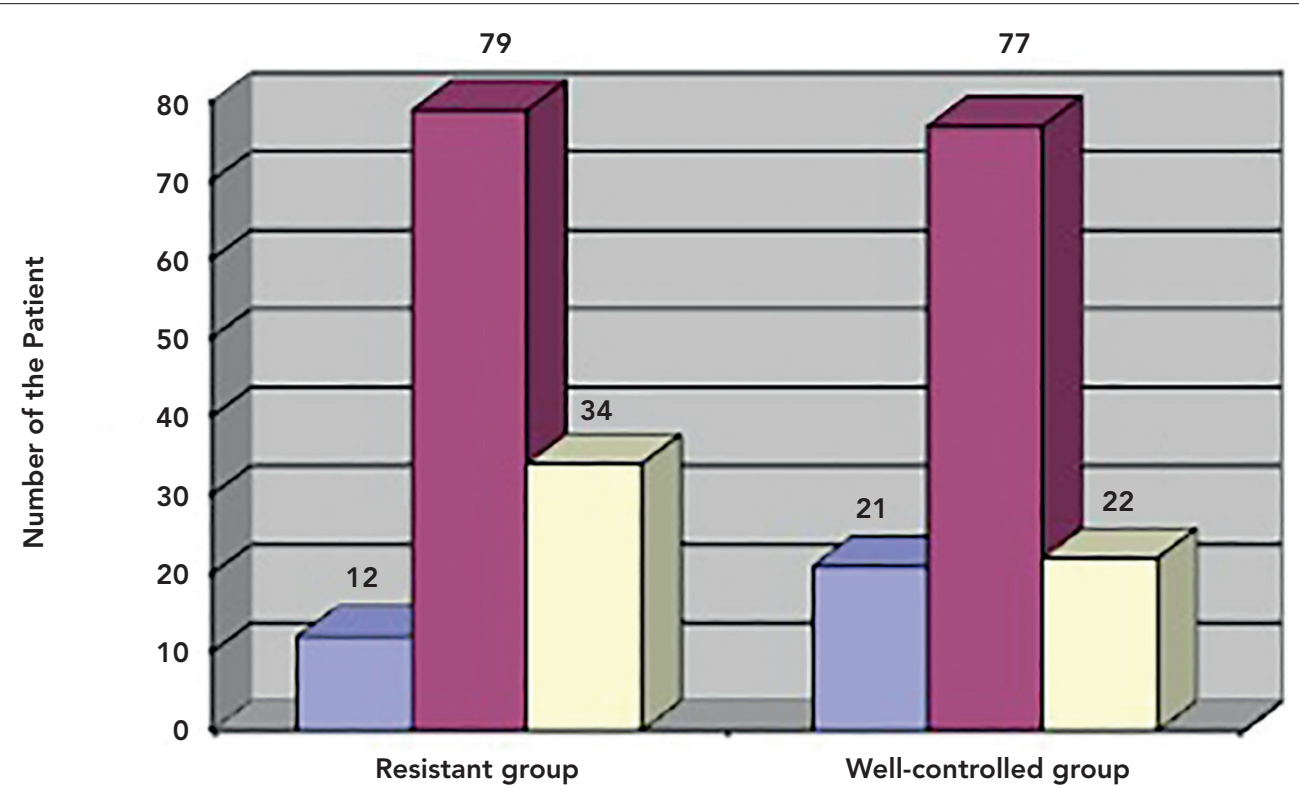

\begin{tabular}{|lll|}
\hline DSingle & a Double & o Three or more \\
\hline
\end{tabular}

Figure 2. Distribution of patients according to seizure diversity 
between the groups $(p<0.05)$. While the rate of single seizure was higher in the well-controlled group (63.6\%), the rate of two seizures was highest in both groups. The rate of single seizure was higher in the well-controlled group (63.6\%), whereas the rate of two seizures was highest in both groups. The distribution of patients with respect to seizure diversity is shown in Table 2 and Figure 2.

\section{DISCUSSION}

In addition to being an important disorder that causes serious deterioration in the quality of life, resistant epilepsy also brings along psychiatric problems such as depression, low school performance, and behavioral disorders. This situation emotionally affects many parents (23). In addition, resistant epilepsy causes medical problems, some of which are potentially life-threatening, such as aspiration due to uncontrolled seizures, cardiac arrhythmias, electrolyte imbalance, brain edema, renal failure, unexplained sudden death, and resistant status epilepticus (24). In this respect, the evaluation of the initial seizure type and the variety of seizures that may play a role in the development of resistance in patients with epilepsy is of great importance for the clinician who follows and treats them.

In the previous studies, when we evaluated the initial seizure types, which is an important criterion focused on, together with the literature, myoclonic seizure was the most common seizure type in the resistant epilepsy group in one study (25), whereas focal onset seizure was the most common seizure type in another study by another group $(26,27)$, and generalized tonic seizure was found to be the most common seizure type in another study $(24,28,29)$. Udani et al. (30) and Huttenlocher et al. (31) found no relationship between the type of initial seizure and the development of resistance. Singhvi et al. (32) found that focus-related seizure is a poor prognostic factor in the development of resistance in adults. There was no consensus between the studies. In our study, myoclonic seizure was the most common seizure type initially in patients with resistant epilepsy, a finding which supported some studies, and generalized and generalized tonic seizures with focal onset in equal amounts were the second most common seizure types. The reason for these differences between the literature is the experience and knowledge of the person who recognizes the seizure. Because most of these seizures are not seen by the physician, they are described by the family.

It is emphasized that there is a significant relationship between seizure diversity and resistance development. Eriksson et al. (2) and a number of other studies noted that seizure control is the weakest in case of the combination of more than one seizure type $(30,31)$. Steffenburg et al. (33) showed that the number of seizure types (seizure variety in the same patient) alone increases the risk of resistant epilepsy. In our study, similar to the literature, it was found that patients with three or more different seizures were more frequent in the resistant group, and that there was a significant relationship between seizure diversity and resistant epilepsy $(p<0.05)$.

In conclusion, resistant epilepsy is an important disorder that causes serious deterioration in the quality of life as well as psychiatric problems such as depression, low school success, and behavioral disorders. This situation is emotionally taxing for many parents (23). Additionally, resistant epilepsy, aspiration due to uncontrolled seizures, cardiac arrhythmias, electrolyte imbalance, brain edema, renal failure, unexplained sudden death, and some of them cause potential life-threatening medical problems, such as resistant status epilepticus (24).

Considering all these negative conditions, early identification of children at high risk of developing resistant epilepsy may help in the consideration of different treatment methods, such as parental support and care. Simultaneously, as the patients in the resistant group continue to have seizures for a long time and use a large number of drugs, the result is that their medical, social, and economic dimensions are severe. There is also a high risk of drug side effects and frequent behavioral and psychological problems. Therefore, if it is possible to predict which patient group will not respond well to medical treatment, different treatment methods such as early next generation antiepileptic use, vagal nerve stimulation, ketogenic diet, and appropriate cases can be applied to this patient group in contrast to other patients $(34,35-$ 37). If the criteria that may be risk factors for resistance development are well defined, they will help guide clinicians in the future.

\section{CONCLUSION}

Clinicians' assessment of the initial seizure type and seizure variety of patients diagnosed with epilepsy is important for the follow-up and treatment of patients.

Ethics Committee Approval: Ethics committee approval was received for this study from the Ethics Committee of Bursa Uludağ University School of Medicine (Date: 30/09/2014 - Number: 2014-18/3).

Informed Consent: Informed consent was not taken from patients due to the retrospective nature of the study.

Peer-review: Externally peer-reviewed.

Author Contributions: Concept - F.Ç.Ç.; Design - F.Ç.Ç.; Supervision M.S.O.; Resources - F.Ç.Ç.; Data Collection and/or Processing - F.Ç.Ç.; Analysis and/or Interpretation - M.S.O.; Literature Search - F.Ç.Ç.; Writing Manuscript - F.Ç.Ç.; Critical Review - M.S.O.

Conflict of Interest: The authors have no conflict of interest to declare.

Financial Disclosure: The authors declared that this study has received no financial support.

\section{REFERENCES}

1. Naderi S, Acar F, Mertol T, Arda MN. Functional anatomy of the spine by Avicenna in his eleventh century treatise "Al-Qanun fial-Tibb" (The Canons of Medicine). Neurosurgery 2003; 52: 1449-53. [CrossRef]

2. Eriksson KJ, Koivikko MJ. Prevalence, classification, and severity of epilepsy and epileptic syndromes in children. Epilepsia 1997; 38: 1275-82. [CrossRef]

3. Basagaoglu I, Karaca S, Salihoglu Z. Anesthesia techniques in the fifteenth century by Serafeddin Sabuncuoglu. Anesth Analg 2006; 102: 28-9. [CrossRef]

4. Asadi-Pooya AA, Ghaffari A. Do patients with epilepsy believe they need specific dietary restrictions? Epilepsy Behav 2004; 5: 945-8. [CrossRef]

5. Majumdar SK. Corpus Hippocraticum 'on the sacred disease' Bull Indian Inst Hist Med Hyderabad 1998; 28: 111-8.

6. Cerić I, Mehić-Basara N. Ibn Sina--psychology and psychological disorders. Med Arh 1997; 51: 21-3.

7. Durá TT, Yoldi ME, Gallinas VF. Incidence of epilepsy in 0-15 yearolds. An Pediatr 2007; 67: 37-43. [CrossRef] 
8. Engel J, Jr. Seizures and Epilepsy. In: Plum F (ed). Contemporary neurology series, vol 31. Philedelphia: F.A. davis Company, 1989; 536.

9. Kwong KL, Chak WK, Wong SN, So KT. Epidemiology of childhood epilepsy in a cohort of 309 Chinese children. Pediatr Neurol 2001; 24: 276-82. [CrossRef]

10. Silverstein FS, Jensen FE. Neonatal seizures. Ann Neurol 2007; 62 112-20. [CrossRef]

11. Raspall-Chaure M, Chin RFM, Neville BG, Bedford H, Scott RC. The epidemiology of convulsive status epilepticus in children: a critical review. Epilepsia 2007; 48: 1652-63. [CrossRef]

12. Rodriguez AJ. Pediatric sleep and epilepsy. Curr Neurol Neurosci Rep 2007; 7: 342-7. [CrossRef]

13. Mac TL, Tran DS, Quet F, Odermatt P, Preux PM, Tan CT. Epidemiology, aetiology and clinical management of epilepsy in Asia: a systematic review. Lancet Neurol 2007; 6: 533-43. [CrossRef]

14. DiMario FJ Jr. Paroxysmal nonepileptic events of childhood. Semin Pediatr Neurol 2006; 13: 208-21. [CrossRef]

15. Wirrell E, Farrell K, Whiting S. The epileptic encephalopathies of infancy and childhood. Can J Neurol Sci 2005; 32: 409-18. [CrossRef]

16. Gardiner M. Genetics of idiopathic generalized epilepsies. Epilepsia 2005; 46: 15-20. [CrossRef]

17. Hirsch E. Childhood epilepsy syndromes with both focal and generalized seizures. Acta Neurol Scand Suppl 2005; 181: 52-6. [CrossRef]

18. Berg AT. Defining intractable epilepsy. Adv Neurol 2006; 97: 5-10.

19. Berg AT, Kelly MM. Defining intractability: comparisons among published definitions. Epilepsia 2006; 47: 431-6. [CrossRef]

20. French JA. Refractory epilepsy: one size does not fit all. Epilepsy Curr 2006; 6: 177-80. [CrossRef]

21. Sillanpää M, Schmidt D. Predicting antiepileptic drug response in children with epilepsy. Expert Rev Neurother 2011; 11: 877-85. [CrossRef]

22. Berg AT, Berkovic SF, Brodie MJ, Buchhalter J, Cross JH, van Emde Boas W, et al. Revised terminology and concepts for organization of seizures and epilepsies: Report of the ILAE Commission on Classification and Terminology, 2005-2009. Epilepsia. 2010; 51: 676-85. [CrossRef]

23. Alving J. What is intractable epilepsy? In: Johannessen SI (ed). Intractable epilepsy. Petersfield: Wrightson Biomedical Publishing, 1995: 1-12.
24. Berg AT, Levy SR, Novotny EJ, Shinnar S. Predictors of intractable epilepsy in childhood: a case-control study. Epilepsia 1996; 37: 2430. [CrossRef]

25. Johnston MV. Seizures in Childhood. In: Berhrman RE, Kielgman RM and Jenson HB (eds.) Nelson Textbook of Pediatrics 17th ed. Saunders: 2004 .p 1993-2005.

26. Karen L, Wai K. Early Predictors of Medical Intractability in Childhood Epilepsy. Ped Neurology 2003; 29: 46-52. [CrossRef]

27. Yoko O, Harumi Y. Predictors and Underlying Causes of Medically Intractable Localization-Related Epilepsy in Childhood. Ped Neurology 2000; 24: 209-13. [CrossRef]

28. Gururaj A, Sztriha L, Hertecant J, Eapen V. Clinical predictors of intractable childhood epilepsy. J Psychosom Res 2006; 61: 343-7. [CrossRef]

29. Chawla S, Aneja S, Kashyap R, Mallika V. Etiology and clinical predictors of intractable epilepsy. Pediatr Neurol 2002; 27:86-91. [CrossRef]

30. Udani VP, Dharnidharka V, Nair A, Oka M. Difficult to control epilepsy in childhood: A long term study of 123 cases. Indian Pediatr 1993; 30: 1199-206.

31. Huttenlocher PR, Hapke RJ. A follow-up study of intractable seizures in childhood. Ann Neurol 1990; 28: 699-705. [CrossRef]

32. Singhvi JP, Sawhney IM, Lal V, Pathak A, Prabhakar S. Profile of intractable epilepsy in a tertiary referral center. Neurol India 2000; 48: 351-6.

33. Steffenburg U, Anders $H$, Intractable Epilepsy in a Population-Based Series of Mentally Retarded Children. Epilepsia 1998; 39: 767-75. [CrossRef]

34. Berg AT, Vickrey BG, Testa FM, Levy SR, Shinnar S, DiMario F, et al. How long does it take for epilepsy to become intractable? A prospective investigation. Ann Neurol 2006; 60: 73-9. [CrossRef]

35. Kossoff EH, McGrogan JR, Bluml RM, Pillas DJ, Rubenstein JE, Vining EP. Modified Atkins Diet Is Effective for the Treatment of Intractable Pediatric Epilepsy. Epilepsia 2006; 47: 421-4. [CrossRef]

36. Sarah I, Janet R. Parents caregiving approaches facing a new treatment alternative in severe intractable childhood epilepsy. Seizure 2003; 12: 1-10. [CrossRef]

37. Holmes GL, Engel J Jr. Predicting medical intractability of epilepsy in children: How certain can we be? Neurology 2001; 56: 1430-1. [CrossRef] 